\section{Post-fire forest management in southern Europe: a COST action for gathering and disseminating scientific knowledge}

\author{
Barbati A (1), Arianoutsou M (2), Corona P (1), De Las Heras J (3), \\ Fernandes $\mathbf{P}^{(4)}$, Moreira $F^{(5)}$, Papageorgiou K ${ }^{(6)}$, Vallejo $\mathbf{R}^{(7)}$,' \\ Xanthopoulos $\mathbf{G}^{(8)}$
}

Every year about 45000 forest fires occur in Europe, burning half a million hectares of forests and rural lands; between 1995 and 2004, more than 4 million hectares burned in the Mediterranean Region alone. Post-fire management of burned areas has been given much lesser attention than combating or preventing fires. However, important questions raise public concern and call for sound scientific knowledge to undertake appropriate post-fire actions: e.g., how to evaluate fire damages in economical terms? How to manage burned areas? Is it possible to establish, in the long-term, less flammable and more fire resilient forests and landscapes? To address these questions, a network of researchers and practitioners working in the field of fire ecology and forest management from all around Europe has been established in the frame of "COST Action FP0701-Post-Fire Forest Management in Southern Europe", supported by the European Union Research and Technology Development Framework Program. The Action aims to: i) develop and disseminate scientifically based decision criteria for planning post-fire forest management, from the stand to the landscape level; ii) translate this scientific knowledge into management practices; iii) connect scientists and stakeholders for exchanging experiences, evaluating these practices, and putting them into practice. To achieve these objectives the scientific groups involved will a) review and summarize the current scientific knowledge on post-fire management in Europe, by gathering and evaluating the results of previous and ongoing research; b) translate this knowledge into technical recommendations, by producing thematic reports, a book on the state-of-the-art of scientific knowledge on post fire assessment, and an electronic handbook on post-fire restoration; c) disseminate this knowledge to stakeholders, practitioners and decision makers. Besides publications and a project website already active (http://uaeco.biol.uoa.gr/cost/), training schools and one major conference will be organized. Although focused on Southern Europe, the outcomes of this Action will be crucial for central and northern European countries as well, as climate change and land use changes often leading to more homogeneous and expanding forest areas are already increasing fire hazard in those regions.

Keywords: Post-fire forest management, Post-fire restoration and rehabilitation, Forest and landscape resilience, Knowledge transfer, Southern Europe

\section{Introduction}

Forest fires rank at the top list of all European forest problems: every year about 45000 forest fires occur in Europe, burning ca. 0.5 million hectares of forests and other rural lands (Camia et al. 2008). Between 1995 and 2004, more than 4 million hectares burned in the Mediterranean Region alone, corresponding to an area larger than the Netherlands. Besides social and environmental impacts, forest fires also produce considerable economic damages due to: i) the huge amount of resources spent in fire suppression and prevention; ii) the loss of commercial value of damaged wood products; iii) the costs related to loss of public non-market services (i.e., biodiversity protection, water cycle regulation, supply of recreational areas, soil protection, carbon sequestration, etc.)

The post-fire management of burned areas has been given much lesser attention than fire suppression and prevention in Europe, despite important questions raising public concern and demanding scientific-based knowledge: e.g., how to evaluate fire damages in economical terms? What are the most suitable short-term intervention techniques to minimise soil erosion and runoff? How to manage burned trees and burned areas? How to approach the long-term planning of ecosystem restoration? How to restore forests and landscapes to reduce future fire hazard? On the other hand, wildfires can be regarded also as an opportunity to plan and establish less flammable and more resi-
(1) Dip.to di Scienze dell'Ambiente Forestale e delle sue Risorse, University of Tuscia, I-01100 Viterbo, Italy; (2) Terrestrial Ecology Group, Faculty of Biology, National and Kapodistrian University of Athens, 15784 Athens, Greece; (3) Escuela Tecnica Superior de Ingenieros Agronomos, University of Castilla-La Mancha, 02071 Albacete, Spain; (4) Dep.to Florestal \& Centro de Investiigação e de Tecnologias Agro-Ambientais e Biológicas, Universidade de Trás-os-Montes e Alto Douro (UTAD), Vila Real, 5001-801 Portugal; (5) Centre of Applied Ecology, Institute of Agronomy, Technical University of Lisbon, 1349-017 Lisbon, Portugal, (6) Dep. of Forests, Forest Fire Protection Office, 1414 Nicosia, Cyprus; (7) Fundacion CEAM, Parque Tecnologico, 46980 Paterna, Spain; (8) National Agricultural Research Foundation, Institute of Mediterranean Forest Ecosystems and Forest Products Technology, 11528 Athens, Greece

@ Anna Barbati (barbati.sisfor@unitus.it)

Received: Oct 30, 2009 - Accepted: Nov 12, 2009

Citation: Barbati A, Arianoutsou M, Corona $P$, De Las Heras J, Fernandes P, Moreira F, Papageorgiou K, Vallejo R, Xanthopoulos G, 2010. Post-fire forest management in southern Europe: a COST action for gathering and disseminating scientific knowledge. iForest 3: 5-7 [online: 2010-01-22] URL: http://www.sisef.it/iforest/show.php? id $=523$

lient forests and landscapes in the recently burnt areas.

The high relevance of post-fire management has been recognized in several contexts, e.g., the EU Forest Action Plan, the $4^{\text {th }}$ International Wildland Fire Conference (http://www.wildfire07.es/); yet, research undertaken on this specific field is still lacking at European level. Though relevant scientific knowledge is available in some countries, mainly of Southern Europe, past research projects did not really allow an effective sharing, integration and dissemination of the information. The EU project EUFIRELAB (http://www.eufirelab.org) was a significant starting point to this, making a preliminary assessment of the state-of-the-art concerning post-fire management techniques and restoration efforts, but much remains to be done.

In this scenario, a network of researchers and practitioners working in the field of fire ecology and forest management from all around Europe has been established in the frame of a "COST Action FP0701-Post-Fire Forest Management in Southern Europe" (duration 2008-2012) as a first initiative to approach the crucial problem of post-fire management in a European perspective. By its nature, the COST Action strongly relies 
on cooperation, knowledge sharing between a large number of countries, capacity building and knowledge transfer, and it is thus expected to be a suitable umbrella for advancing knowledge in this field.

\section{Objectives of the COST Action}

The main goal of the Action is the development and dissemination of scientificallybased decision criteria for post-fire management, from stand-level to landscape-level planning.

The short term expected result is to increase the scientific basis for undertaking appropriate post-fire management action in Southern Europe, whereas the long term expected impact is to improve the effectiveness in restoring burned areas and reduce fire hazard in European forests and landscapes.

These objectives will be mainly achieved by networking human resources from 16 European countries (about 130 participants join the project), in order to:

1. gather the scientific basis for post-fire management by: i) reviewing, assembling and integrating findings of previous and ongoing research; the COST Action is notably expected to benefit from and complement the activities of the PHOENIX network (http://www.phoenix-efi.org/) and FIRE PARADOX project (http://www.fireparadox.org/); ii) compiling questionnaires and on-line databases to collect new information;

2. transfer this knowledge into technical recommendations to be shared across Europe, by producing thematic reports, a book on the state-of-the-art of scientific knowledge on post-fire assessment, and an electronic handbook on post-fire restoration;

3. disseminate this knowledge to land managers, stakeholders, national and regional governments, by organizing training schools for knowledge transfer on post-fire management for the Southern European conditions and one major conference.

An Action website has been set up (http://uaeco.biol.uoa.gr/cost/) to network Action participants and to ensure the dissemination or exploitation of the Action results. This site is used to announce activities (training schools, meetings, conferences), to facilitate communication between the participants (discussion papers, databases) and to disseminate results (technical reports, electronic handbook).

\section{Issues addressed by the COST Action and approach}

The Action develops through five working groups (WGs). All participants take part in WGs according to their field of expertise or interest. Single WGs address specific scientific and technical issues, according to the approaches summarized below.

\section{WG1 - Fire hazard and resilience}

The main goal is to assess fire hazard and combustibility of forest stands and broad land cover types as well as their fire resilience, in order to be able to promote less fire prone forests and landscapes.

Concerning fire hazard the following activities are planned:

- to review available knowledge on fire preference/avoidance of different forest and land cover types, using information gathered through the PHOENIX network as basis;

- to organize a report on fire hazard and combustibility in different forest types, based on expert opinion and on agreed classification criteria in terms of combustibility and fire hazard and/or on literature findings;

- to analyze fire frequencies and land cover changes, using the Corine Land Cover (1990-2000) and the EU fire database maintained within the European Forest Fire Information System (EFFIS) at the Joint Research Centre (JRC) of Ispra-Italy (more than 10 years of observations are available, including information of fire frequency).

The fire resilience of forest stands and land cover types will be assessed, by gathering the results of different research initiatives and available literature. More fire-resilient forests (i.e., with greater ability to resist fire or recover from it) will imply less economic costs in post-fire restoration, so this knowledge is essential. Plant traits associated with fire resistance and resilience will be assessed from the available literature and from previous and ongoing projects. An important source of information on this topic was produced by the EUFIRELAB network and the ongoing CIRCE EC project (http://www.circeproject.eu) and the Action will build upon knowledge from these projects (see also Paula et al. 2009).

\section{WG2 - Fire effects and fire severity assessment}

Activities in this WG focus on gathering the results of previous and ongoing scientific research on the effects of fire on soil, vegetation and biodiversity; an additional source of information on fire effects will come from the results of the ongoing project FIRE PARADOX.

\section{WG3 - Economic assessment of damage and current practices in post-fire management}

Three main topics are covered by this WG: i) economic evaluation of fire damages; ii) legal and social issues related to the management of burnt forest areas; iii) post-fire management practices currently applied in Europe.

The economic evaluation of fire damages (i) answers the need to provide information and comparative and harmonized knowledge at European level on how to assess forest fires damages to products and services and direct fire suppression costs. A review of available experiences in Europe for the economic assessment/evaluation of the commercial value of damaged wood and non-wood marketable products and the costs related to loss of non-marketable services will be carried out. In addition, questionnaires specifically targeted to gather information on this issue will be compiled by the National Delegates of COST countries and other interested experts in Europe.

Topic (ii) aims at providing an insight on legal and social issues connected to post-fire management. Again, questionnaires will be used to collect information through COST National delegates. Questionnaires will cover:

- legal issues, e.g., legal constraints regarding land reclamation and/or land use conversion of forest burnt areas; restrictions applied to forest burnt areas to ensure postfire forest regeneration; presence of a regulatory framework allowing forest owners to sue (e.g., electric power companies) for fire damages associated with fixed installations of power lines;

- social issues: involvement of local communities in post-fire recovery activities; role of volunteers in first-aid restoration techniques and/or woodland restoration activities; raising awareness activities concerning forest fire damage and best practices of post-fire management; presence of migration patterns after forest fires.

Topic (iii) is intended to provide an overall picture of current post-fire management practices in Europe. A questionnaire to be compiled by the National Delegates will investigate the types of practices commonly adopted, with distinctive emphasis on:

- post-fire harvest of trees (presence/absence, timing, justification criteria);

- post fire mitigation of soil erosion and flood risk (presence/absence, timing, techniques, justification criteria, monitoring if any);

- silvicultural techniques used to support the post-fire natural regeneration (seeding and resprouting);

- use of active seeding and plantation (timing, criteria, justification);

- control of exotic invasive species (if relevant, type of control techniques) and of the impact of grazing/browsing on regeneration (presence/absence, type of measures)

WG4 - Forest conversion and post-fire management techniques

It addresses two main issues:

- to develop proactive recommendations for target fire-prone forest and shrubland types in Europe in order to promote less flam- 
mable, more resilient, more productive and more diverse ecosystems. The goal is to identify successful options for vegetation and fuel management applicable to a range of management goals (productivity, resilience, biodiversity, etc.); this activity will benefit from findings of WG1 to gain information on combustibility, resilience, potential fire effects, and response mechanisms of different forest and shrubland types in Europe;

- to collect and disseminate information on post-fire restoration projects in Europe through an online database hosted by COST website to be compiled by the project responsible; the database will contain the following main fields of information: general description; geographical location of the study site; environmental characteristics of the study site; degradation impacts (e.g., loss of forest cover, species loss, soil erosion); restoration goals (e.g., biodiversity conservation, fire control, erosion control); restoration practices (e.g., prior action on brush vegetation, soil preparation, planting and seeding); project results (a qualitative assessment made by the responsible of the project on the degree of success of technical operations and social impacts and social perception).

\section{WG5 - Knowledge transfer and monitoring}

The Action will allow putting scientists face to face with key stakeholders by means of a series of activities, organized by the "Dissemination Plan" of the COST Action. Thus, the results from activities under different WGs will be made available to forest and landscape managers, regional and na- tional governments, through different means: publications (a book and an electronic handbook), three training schools and one major final conference. The WG5 coordinates knowledge transfer activities, by organizing the publication content structure, as well as defining the topics to address in training schools and conferences.

\section{Expected impacts of the COST Action}

The COST Action is in its first year of activity. So far, 19 COST countries have ratified the Action (Bulgaria, Cyprus, Former Yugoslav Republic of Macedonia, France, Germany, Greece, Israel, Italy, Latvia, Lithuania, Poland, Portugal, Romania, Slovak Republic, Slovenia, Spain, Switzerland, Turkey and United Kingdom) and 4 institutions from non-COST countries (National Institute of Research in Rural Genius Water and Forests -Tunisia, Joint Research CentreEuropean Commission, SCION-New Zealand, National School of Forest EngineersMorocco).

The objectives of COST Action will be achieved mainly through cooperation between human resources involved in the project. The progress of activities and evaluation of the project objectives achievement are monitored by a Steering Committee group, consisting of the Chair and the ViceChair of the Action, the WGs leaders and the Short-Term Scientific Mission (STSM) coordinator.

The expected benefits of this Action are:

1. to improve the scientific basis for post-fire management options that allow adequate decisions to be taken by stakeholders and managers, from the forest stand to the landscape planning levels; gathering and disseminating the available scientific and technical knowledge at European level is essential to this;

2. to contribute to a better economic evaluation of fire damages, as well as of the costs and benefits of different post-fire management alternatives;

3. to contribute to the establishment of less flammable and more resilient forests in Europe;

4. to contribute to effectively mitigate fire effects in European forests;

5. to contribute to decrease the dimension of the catastrophe that forest fires represent every year in southern Europe.

Although focused on southern Europe, the outcomes of this Action will be crucial for central and northern European countries as well, as climate change and land use changes often leading to more homogeneous and expanding forest areas are already increasing fire hazard in those regions.

\section{References}

Camia A, San-Miguel-Ayanz J, Kucera J, Amatulli $\mathrm{G}$, Boca $\mathrm{R}$, Libertà $\mathrm{G}$, Durrant $\mathrm{T}$, Schmuck G, Schulte E, Bucki M (2008). Forest fires in Europe 2007. Joint Research Centre, Institute for Environment and Sustainability, Office for Official Publications of the European Community, Luxembourg, pp. 77.

Paula S, Arianoutsou M, Kazanis D, Tavsanoglu Ç, Lloret F, Buhk C, Ojeda F, Luna B, Moreno JM, Rodrigo A, Espelta JM, Palacio S, Fernàndez-Santos B, Fernandes PM, Pausas JG (2009). Fire-related traits for plant species of the Mediterranean Basin. Ecology 90: 1420. - doi: 10.1890/08-1309.1 